\title{
The Hematological Parameters of the Prussian Carp (Carassius gibelio, (Bloch, 1782)) Under the Zaporizhian (Dnipro) Reservoir Conditions
}

\author{
Viktoriia Oleksandrivna Kurchenko ${ }^{1, *}\left(\mathbb{D}\right.$, Tatiana Sergiivna Sharamok ${ }^{1}$
}

${ }^{1}$ Oles Honchar Dnipro National University, Gagarin Ave, 72, Dnipro, 49050, Ukraine

\author{
Article History \\ Received 19 May 2020 \\ Accepted 16 October 2020 \\ First Online 20 October 2020 \\ Corresponding Author \\ Tel.: +380993011632 \\ E-mail: \\ kurchenko.viktoriia.3@gmail.com
}

\author{
Keywords \\ Blood \\ Erythrocytes \\ Leukocyte formula \\ Biochemical parameters
}

\begin{abstract}
Hematological parameters are quite effective and informative for determining the health status of fish populations. They respond quickly to changes in habitats of different nature. The Prussian carp is one of the most widespread species in the Ukrainian reservoirs. Currently, the researches of hematological changes of this species in the modern conditions of the Zaporizhyian (Dnipro) reservoir are quite relevant. During the research the ecological classification of surface water quality in Ukraine, it was found that the water in the Samara Bay is characterized as "moderately polluted", and in the lower part of the reservoir it is "slightly polluted". The concentration of almost all investigated heavy metals in the water of the Samara Bay is higher compared to the lower part of the reservoir. The number of erythrocytes and hemoglobin content in the blood of Samara Bay fish were lower by $22.4 \%$ and $44 \%$, respectively, compared to fish in the lower part of the Zaporizhian (Dnipro) reservoir, and the erythrocyte sedimentation rate was higher by $81.8 \%$. In the Prussian carp from the silver Zaporizhian (Dnipro) reservoir, neutrophilic leukocytosis with a shift to the left was observed, which is usually characteristic of inflammatory processes and various intoxications. There were also statistically significant deviations in the activity of ALT and AST in the blood plasma of fish in the Samara Bay, which may indicate a chronic impact of a complex of anthropogenic factors on fish, especially on the function of the liver, which serves as a detoxifying organ.
\end{abstract}

\section{Introduction}

It is known that anthropogenic changes that occur in aquatic ecosystems affect the physiological state of fish. Blood is an integral system that allows to trace disturbances at different levels of the body's functioning. Species conditions imprint on morphological features and quantitative indicators of red and white blood (Vergolas, 2016). Nowadays, hematological parameters are considered to be effective and sensitive to physiological and pathological changes in fish (Fazio, 2019, Fazio et al., 2020). Given the need to obtain information on the detection and control of stressful situations and diseases, hematological analysis and assessment of fish diseases are important.
The use of hematological status in the diagnosis of fish is possible only when there is information about the ranges of physiological variations in hematological parameters, as well as knowledge of causal relationships between changes in external and internal environment with changes in fish blood pattern (Ahmed et al., 2020, Fazio et al., 2020).

Hematological parameters are potential biomarkers that respond to toxic effects of various natures (Fazio et al., 2020, Ventura et al., 2018).

Therefore, hematological analysis is important as an adjunct in the diagnosis of fish health. Currently, there is a need for research in this area to identify and control stressful situations and fish diseases. 
The Prussian carp is the dominant industrial species of the Zaporizhian (Dnipro) reservoir. Certain indicators of the fish blood, despite its ecological plasticity, are an objective indicator of the health status of the population of this species and the conditions of its existence.

The purpose of this work was to research the cytometric and hemato-biochemical parameters of the blood of the Prussian carp (Carassius gibelio (Bloch, 1782)) in modern conditions of the Zaporizhian (Dnipro) reservoir.

\section{Materials and Methods}

The surveys were conducted in the summer at two fishery sites located in the Samara Bay (48 $53^{\prime} 40.21^{\prime \prime} \mathrm{N}$; $\left.35^{\circ} 18^{\prime} 73.20 \mathrm{E}\right)$ and the lower part of the Zaporizhian (Dnipro) reservoir (village Viyskove), $\left(48^{\circ} 22^{\prime} 30.75^{\prime \prime} \mathrm{N}\right.$; $35^{\circ} 20^{\prime} 80.05 \mathrm{E}$ ) (Figure 1).

Hydrochemical researches of water were conducted according to generally accepted methods (Arsan et al., 2006) Indicators of chemical composition of water were compared with regulatory indicators for fishery needs in Ukraine (SOU 05.01-37-385: 2006).

The content of heavy metals in the samples was determined by atomic absorption spectrophotometry on a spectrophotometer C-115M1 (Tsyupko, 1991).

The fishing was carried out by standard joint nets with an eye step of $30-45 \mathrm{~mm}$. The subject of the research were four-year-old individuals of Carassius gibelio (Bloch, 1782) of both sexes.

The weighted average of the industrial length of the Prussian carp individuals was $20.37 \pm 0.37 \mathrm{~cm}$. The weighted average weight of individuals was $147.42 \pm 10.14 \mathrm{~g}$.

In total, 100 fish specimens from each site were examined. Blood was taken from the tail vein. After preparing the smear, it was stained in a modified way (Kurchenko et al., 2019). The identification of the formed blood elements was performed using an atlas (Ivanova, 1989). The photographs were taken using a SciencelabT500 5.17M digital camera that connected to the Ulab XY-B2TLED microscope at 400 magnification.

We have viewed 200 fields of view on the preparations. The following parameters were determined: large longitudinal (D) and small transverse (d) diameters of mature erythrocytes, erythrocyte area (S), erythrocyte nucleus area (s), nuclear cytoplasmic ratio $(s / S)$. The calculations were performed using ScienceLabView7. Statistical processing of the obtained results was performed according to conventional methods of variational statistics.

The hematological and biochemical researches were performed using conventional methods (Davydov et al., 2006). The following indicators were determined: total erythrocyte count (test tube method in Goryaev's chamber), hemoglobin (hemoglobin determination method by Sali, color index, erythrocyte sedimentation

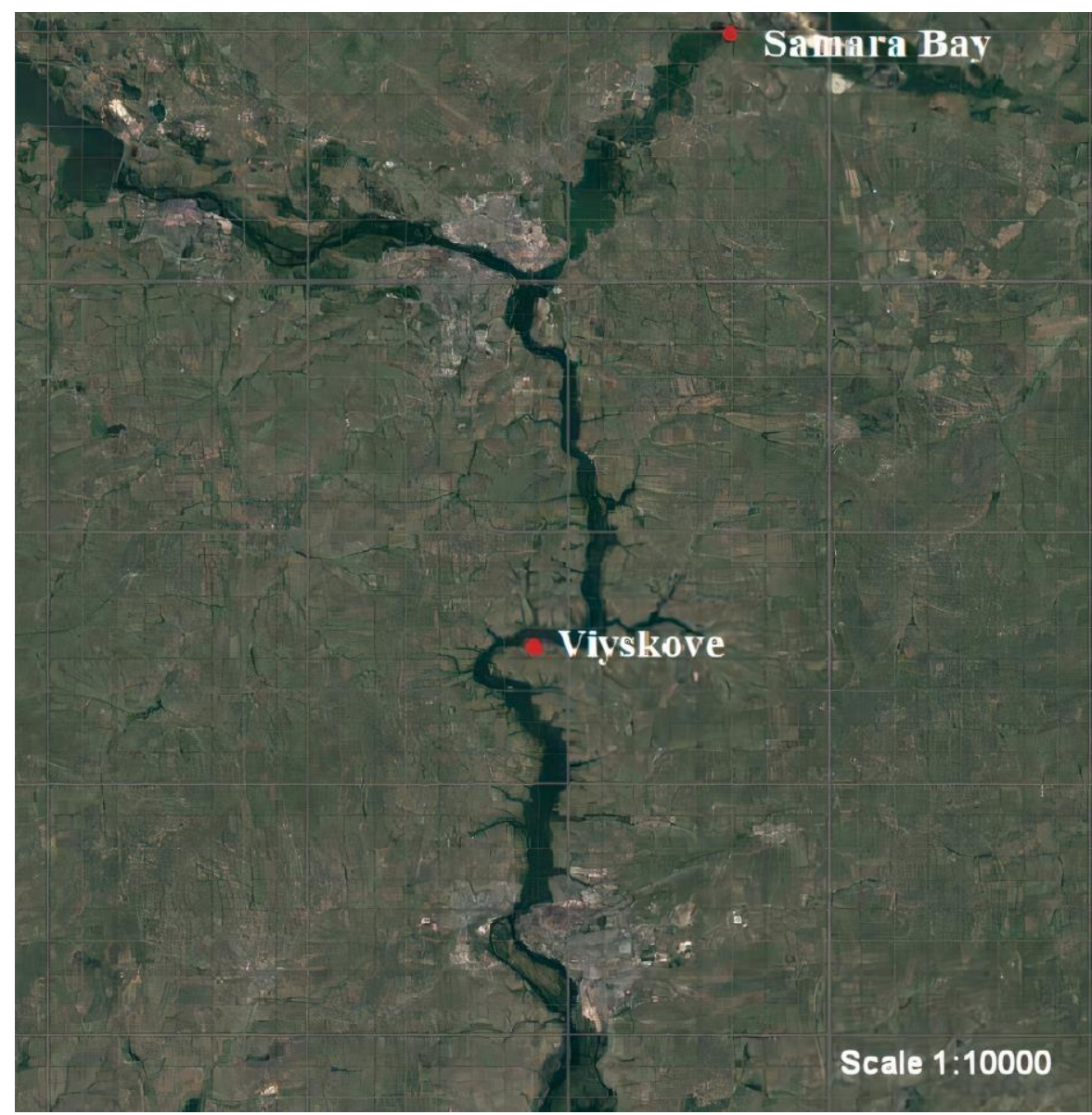

Figure 1. Scheme of the Zaporizhian (Dnipro) reservoir 
rate (Panchenkov micrometer), total leukocyte count (direct leukocyte count method).

The biochemical researches were performed on OLYMPUS AU400 and AU480 automatic analyzers Beckman Coulter (USA), Beckman Coulter reagents in the laboratory "INVITRO" (Dnipro). Methods for determining the activity of alanine aminotransferase $(A L T)$, aspartate aminotransferase (ACT), total protein, protein ratio, glucose are based on the recommendations of the International Federation of Clinical Chemistry (IFCC).

Bioethical standards were not violated during the research. It was performed in accordance with the Regulations on the Ethics Committee (Bioethics) in Ukraine (Regulations on the Ethics Committee (Bioethics), 2019).

\section{Results and Discussion}

The researches have shown that according to the ecological classification of surface water quality of Ukraine, water in the Samara Bay belongs to class III, 4th quality category ("moderately polluted"), and in the lower part (near the Viyskove village) - class II, 2nd category ("slightly contaminated").

It was found that the concentration of almost all investigated heavy metals in the water of the Samara Bay is higher compared to the lower part of the Zaporizhian reservoir. There were statistically significant differences between the content of copper (35\%), zinc (42\%), nickel (65\%), lead (75\%) and cadmium (85\%) in the two areas of the reservoir $(P<0.05)$.

Cytological examination showed that normally on the blood preparations, the Prussian carp erythrocytes had a clear oviduct shape with smooth contours, a dark purple nucleus that was located in the center of the cell. No significant differences were observed between cytometric indices of fish cells from the lower part of the reservoir and from the Samara Bay. Although, in general, in the fish from the Samara Bay values of all researched parameters were slightly higher than in the lower part of the reservoir (Table 1).

In the resrarch of the hematologic indices, the number of erythrocytes in the Prussian carp from the Samara Bay was $28.8 \%$ higher than in the fish from the lower part and averaged 2.9 million / $\mu$ l. It is known that fish exhibit certain fluctuations in erythrocyte count and hemoglobin concentration depending on systematic position, age, activity, state of the organism, ecology of the species, season, physico-chemical factors of the environment, and others (Witeska, 2013, Fazio et al., 2020). The amount of hemoglobin in the blood of the Prussian carp from the Samara Bay was lower by $44 \%$ than in the blood of the Prussian carp from the lower part of the reservoir (Table 2). Without this indicator it is impossible to estimate the intensity of metabolic processes in the body. A decrease in hemoglobin indicates a suppression of hematopoiesis, which is often an unfavorable sign. At deficiency or excess of hemoglobin metabolic processes in an organism of fishes are broken (Khabarov, 2005).

The color index reflects the relative content of hemoglobin in erythrocytes and is a very important diagnostic indicator for fatigue, violations of hydrochemical regimes in reservoirs and poisoning (Davydov et al., 2006). In this research, this index was almost indistinguishable in fish from both sites and was 0.75 in the lower part and 0.76 in the Samara Bay.

During the hematological examination of the Prussian carp from the Samara Bay the rate of erythrocyte sedimentation rate was higher by $81.8 \%$ compared to the Prussian carp from the lower part of the reservoir, which may indicate the presence of an inflammatory process in the body.

In the Samara Bay there was a tendency to increase the total number of leukocytes in comparison with the

Table 1. The cytometric indices of erythrocytes of the Prussian carp from Zaporizhian (Dnipro) reservoir

\begin{tabular}{llcc}
\hline № & Indicator (average value) & The Samara Bay & The lower part \\
\hline 1. & Cell area, $\mu \mathrm{m}^{2}$ & $80.95 \pm 0.94$ & $78.07 \pm 1.13$ \\
2. & Large cell diameter, $\mu \mathrm{m}$ & $12.13 \pm 0.09$ & $11.59 \pm 0.09$ \\
3. & Small cell diameter, $\mu \mathrm{m}$ & $8.35 \pm 0.08$ & $8.44 \pm 0.11$ \\
4. & Nucleus area, $\mu \mathrm{m}^{2}$ & $15.65 \pm 0.31$ & $12.97 \pm 0.38$ \\
5. & Large nucleus diameter, $\mu \mathrm{m}$ & $5.61 \pm 0.07$ & $4.91 \pm 0.09$ \\
6. & Small nucleus diameter, $\mu \mathrm{m}$ & $3.42 \pm 0.05$ & $3.23 \pm 0.09$ \\
7. & Nuclear-cytoplasmic ratio & $0.194 \pm 0.004$ & $0.166 \pm 0.005$ \\
\hline
\end{tabular}

Table 2. The hematological indices of the Prussian carp from the Zaporizhian (Dnipro) reservoir

\begin{tabular}{lcc}
\hline Indicator & The lower part & The Samara Bay \\
\hline Erythrocytes million / $\mu \mathrm{l}$ & $2.9 \pm 0.6$ & $2.25 \pm 0.9$ \\
Hemoglobin, g / & $72.5 \pm 1.4^{*}$ & $40.75 \pm 0.9^{*}$ \\
Color indicator & $0.75 \pm 0.3$ & $0.76 \pm 0.3$ \\
Leukocytes thousand / $\mu \mathrm{l}$ & $2.07 \pm 1.2$ & $2.6 \pm 1.4$ \\
Erythrocyte sedimentation rate mm / h & $2.75 \pm 1.7^{*}$ & $5.0 \pm 2.1^{*}$ \\
\hline
\end{tabular}

*- The difference between the indicators is statistically significant, at $\mathrm{P}<{ }^{\prime} 0.05$ 
Prussian carp from the lower part (Table 3). This may indicate an increased protective function of blood in the body under the action of chemical toxicants.

The predominant white blood cells of the fish were lymphocytes, which accounted for 69\% in the lower region and $73 \%$ in the fish from the Samara Bay (Fedonenko et al., 2017).

A reliable criterion for assessing the physiological state of fish is the deviation in the ratio of different forms of leukocytes, in particular the leukocyte shift index (LSI).

Changing of the ILD in one direction or another from a conditional norm is a sign of disease or increased negative environmental pressure. The ILD of the Prussian carp from the lower part of the Zaporizhian reservoir was 0.04 , and in the species from the Samara Bay - 0.05, indicating a shift to the left in the leukocyte formula. Neutrophilic leukocytosis with a shift to the left is observed, as a rule, in the form of inflammatory processes and various intoxication (Moiseenko, 2000).
The fish from the lower part of the reservoir had a tendency to increase the content of total protein in blood plasma (Figure 2). High protein content within the established limits is a favorable sign, significant loss of protein is associated with a decrease in viability and may be accompanied by the death of fish. Of great diagnostic importance is the protein factor - the ratio of the amount of albumin to the amount of globulin.

In the fish from both sites, it was within normal range. In fish from both study areas, it was within normal limits and was 1.14.

Increased activity of alanine aminotransferase (ALT) and aspartate aminotransferase (AST) are markers that indicate disorders and damage to muscles, liver and other internal organs (Bichareva, 2011). The obtained results indicate that the indicators of ALT activity in the blood serum of the Prussian carp from the Samara Bay exceeded by $32 \%$ the indicators of fish caught in the lower part of the reservoir (Figure3). In this regard, ALT is considered to be an enzyme indicator or a marker of

Table 3. The indicators of leukocyte blood formula of the Prussian carp from the Zaporizhian (Dnipro) reservoir

\begin{tabular}{lcc}
\hline Indicator,\% & The lower part & The Samara Bay \\
\hline Segmental neutrophils & $25.0 \pm 0.2$ & $22.0 \pm 0.3$ \\
Rod-shaped neutrophils & $1.0 \pm 0.5$ & $1.0 \pm 0.2$ \\
Lymphocytes & $68.5 \pm 0.5$ & $72.4 \pm 0.8$ \\
Monocytes & $5.5 \pm 0.2$ & $4.6 \pm 0.2$ \\
\hline
\end{tabular}

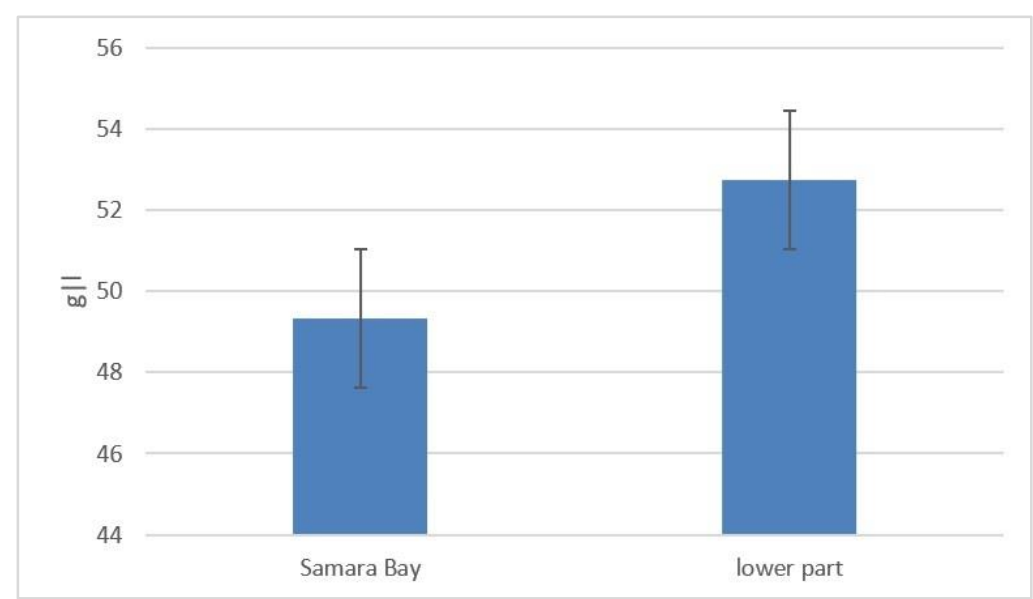

Figure 2. The content of total protein in the blood plasma of the Prussian carp from the Zaporizhian (Dnipro) reservoir.
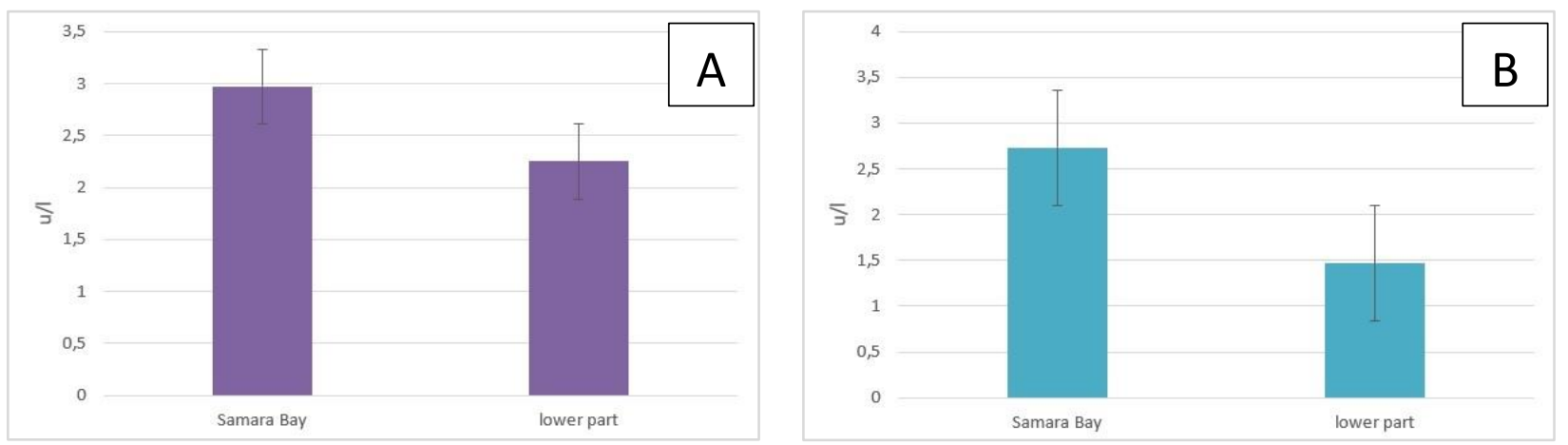

Figure 3. The content of ALT (A) and AST (B) in the blood plasma of the Prussian carp from the Zaporizhian (Dnipro) reservoir 
liver dysfunction of any nature. In a healthy body, the content of ALT in the blood is low (Kamyshnikov, 2004, Shatunovskii, 1980).

The amount of AST in the blood plasma of fish from the Samara Bay of the reservoir was almost $86 \%$ higher compared to the fish of the lower part of the reservoir. It can be assumed that the increase in the level of AST in the blood serum of fish is associated with changes in lipid peroxidation processes in muscle tissue and liver, due to increased anthropogenic pressure, deterioration of the environment (Guliyev \& Melyakina, 2014).

Quantitative indicators of glucose in the blood of fish are an important indicator of carbohydrate metabolism. The glucose content of experimental fish from both parts of the reservoir was low, and was within physiological norms. Smaller values of this indicator were recorded by $32 \%$ in fish from the Samara Bay, compared to the corresponding indicators of the lower part of the Zaporizhian reservoir (Figure 4).

\section{Conclusions}

According to the ecological assessment, the water of the Samara Bay of the Zaporizhian (Dnipro) reservoir in is characterized as "moderately polluted", and in the lower part of the reservoir - "slightly polluted". The concentration of almost all researched heavy metals in the water of the Samara Bay is higher compared to the lower part of the reservoir. Statistically significant differences were found between the content of copper (35\%), zinc (42\%), nickel (65\%), lead (75\%) and cadmium $(85 \%)$ in the two areas of the reservoir.

The researches of hematological parameters of the Prussian carp from the Samara Bay indicate the course of anemic and inflammatory processes in fish. The number of erythrocytes and hemoglobin content in the fish of the Samara Bay were lower by $22.4 \%$ and $44 \%$, respectively, compared with the fish from the lower part of the Zaporizhian (Dnipro) reservoir, and the sedimentation rate of erythrocytes was higher by $81.8 \%$.

In the Prussian carp from the Zaporizhian (Dnipro) reservoir, neutrophilic leukocytosis with a shift to the left was observed, which is usually characteristic of inflammatory processes and various intoxications.

Statistically significant deviations in the activity of ALT and AST indicate the effect of toxicants on fish from the Samara Bay, primarily on the function of the liver, which serves as a detoxifying organ. Elevated liver complex in fish caught from the Samara Bay may indicate a chronic impact of a complex of anthropogenic factors.

\section{Acknowledgements}

The authors sincerely thank all our reviewers. This study was funded by the Ministry of Education and Science of Ukraine. Scientific research work «Ecological bases of rational resource use and development of the agricultural complex of the Prydniprovia in the field of aquaculture, fish farming and fishing» (1-640-19).

\section{References}

Ahmed, I., Reshi, Q.M. \& Fazio F. (2020). The influence of the endogenous and exogenous factors on hematological parameters in different fish species: a review. Springer Nature Switzerland AG 2020. Advance online publication. https://doi.org/10.1007/s10499-01900501-3

Arsan, O.M., Davydov, O.Y., Dyachenko, T.M. and others. (2006). Methods of hydroecological research of surface waters. (Romanenko V. D.). Kyiv.

Bichareva, O.N. (2011). Activity of serum transferases in Cyprinidae fishes. Nature sciences, 34, 96-100.

Biktasheva, F.H. \& Latypova, G.F. (2013). Hematological indicators of representatives of predatory fish in the natural park of lake Asylykul. Proceedings of the Orenburg State Agrarian University, 1 (39), 72-73. https://cyberleninka.ru/article/n/gematologicheskiepokazateli-predstaviteley-hischnyh-ryb-prirodnogoparka-ozera-asylykul/viewer

Davydov, O.N., Temnikhanov, Yu. D. \& Kurovskaya, L.Ya. (2006). Fish blood pathology. Kiev.

Fazio, F. (2019). Fish hematology analysis as an important tool of aquaculture: A review. Aquaculture 500, 237-242. https://doi.org/10.1016/j.aquaculture.2018.10.030

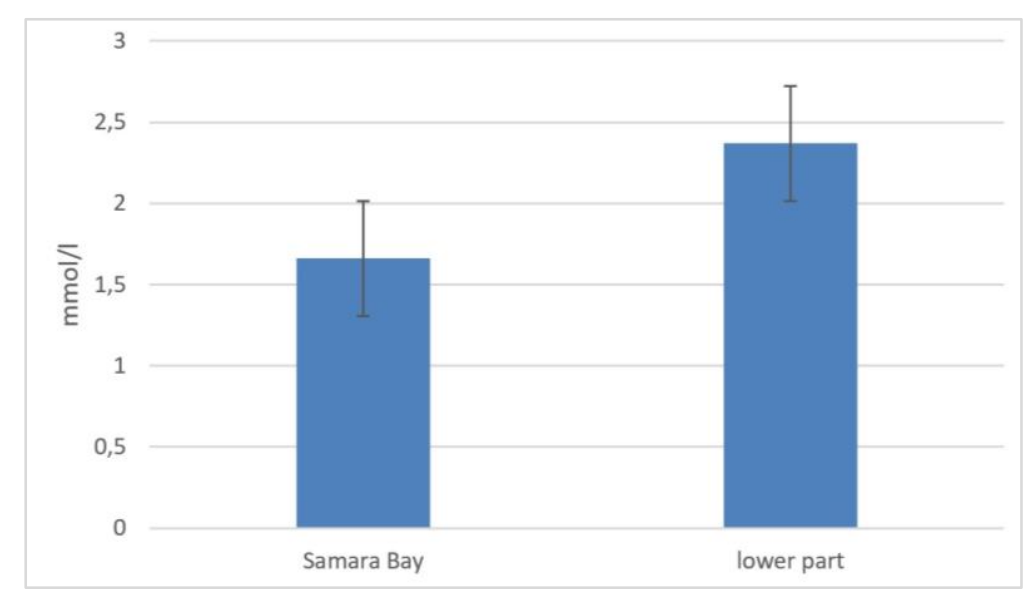

Figure 4. The glucose content in blood plasma of the Prussian carp from the Zaporizhian (Dnipro) reservoir 
Fazio, F., Lanteri, G., Saoca, C., Iaria, C., Piccione, G., Orefice, T., Calabrese, E., \& Vazzana, I. (2020). Individual variability of blood parameters in striped bass Morone saxatilis: possible differences related to weight and length. Springer Nature Switzerland AG 2020. Advance online publication. https://doi.org/10.1007/s10499020-00550-z

Fedonenko, E.V., Sharamok, T.S. \& Ananyeva, T.V. (2017). Features of the leukocyte formula in some carp fish from the Zaporizhian reservoir. Proceedings of VNIRO: commercial species and their biology, 167, 59-65. http://www.vniro.ru/ru/periodicheskie-izdaniya/trudyvniro/trudy-vniro-nauchnyj-zhurnal-tom-167-2017otsenka-sostoyaniya-zdorovya-gidrobiontov

Guliev, R.A. \& Melyakina, E.I. (2014). Some biochemical parameters of the fish blood in the Volga delta. AGTU Bulletin. Ser.: Fisheries, 2, 85-91. https://cyberleninka.ru/article/n/nekotoryebiohimicheskie-pokazateli-krovi-ryb-delty-volgi/viewer Ivanova, N.T. (1989). Atlas of the fish blood cells. Moscow.

Kamyshnikov, V.V. (2014). Handbook of clinical and biochemical studies and laboratory diagnostics. Moscow.

Khabarov, M.V. (2005). The albumin system of the blood serum of ecologically different types of sturgeon fish. Diss. Dr. Biol. sciences. In: Yaroslavl.

Kurchenko, V., Sharamok, T. \& Marenkov, O. (2019). The improvement of blood smears coloring for the determining of fish cytometric blood parameters.
Biological systems. Т. 11. Вип. 1, 15-18. https://doi.org/10.31861/biosystems2019.01.015

Moiseenko, T.I. (2000). Morphological rearrangements of the fish organism under the influence of pollution (in S.Schwartz's theory). Ecology, 6, 463-472.

Regulations on the Ethics Committee (bioethics). (Normative document of the Ministry of Education, Science, Youth and Sports of Ukraine. Order of 19.11.2012 № 1287): Regulatory framework of the Ministry of Education and Science of Ukraine (official website). http://www.mon.gov.ua/ua/activity/63/64/normativno -pravova-baza

Shatunovskii M.I. (1980). Ecological common factors of sea fish metabolism. Moscow.

Tsyupko, F.I. (1991). Instructions for operation on the atomic absorption spectrophotometer C115-M1. Lviv.

Ventura, A.S., Jerônimo, G.T., Ferri, G.H, Benites de Pádua, S., Martins, M.L. \& Ishikawa, M.M. (2018). Erythrocyte parameters and condition factor of Gymnotus spp. (Gymnotiformes: Gymnotidae) under culture conditions. Brazilian Journal of Veterinary Medicine, 40, e20318, 16. https://doi.org/10.29374/2527-2179.bjvm020318

Vergolas, M.R. (2016). Blood as an integral system of the body. Scientific Journal "ScienceRise», 2/1 (19), 7-11. http://dx.doi.org/10.15587/2313-8416.2016.60603

Witeska, M. (2013). Erythrocytes in teleost fishes: a review. Zoology and Ecology,1-4. https://doi.org/10.1080/21658005.2013.846963 